\title{
Exploration of Horizontal Information Transmission through Social Learning in Juvenile Atlantic Spotted Dolphins (Stenella frontalis)
}

\author{
Gaïane L. B. De Brabanter ${ }^{1,2^{*}}$, Denise L. Herzing, ${ }^{2,3}$ and Susan Jarvis ${ }^{1,4}$ \\ ${ }^{1}$ Royal (Dick) School of Veterinary Studies, University of Edinburgh, UK \\ ${ }^{2}$ Wild Dolphin Project, USA \\ ${ }^{3}$ Department of Biological Sciences, Florida Atlantic University, USA \\ ${ }^{4}$ Scotland's Rural College, Edinburgh, UK \\ *Corresponding author (Email: gaiane.de.brabanter@gmail.com)
}

Citation - De Brabanter, G. L. B., Herzing, D. L., \& Jarvis, S. (2017). Exploration of horizontal information transmission through social learning in juvenile Atlantic spotted dolphins (Stenella frontalis). Animal Behavior and Cognition, 4(4), 425-441. https://dx.doi.org/ 10.26451/abc.04.04.03.2017

\begin{abstract}
Although vertical (mother-to-offspring) information transfer has been reported in dolphins, it is unclear whether horizontal information transfer takes place between peers of non-parental individuals. We hypothesized that horizontal information transmission takes place within juvenile social play-forage subgroups and within pairs of juveniles in the form of social learning, as a way for older juveniles to contribute to the further development of younger juveniles' foraging skills. Since 1985, a long-term study in the Bahamas has involved the collection of underwater videos and sound recordings on the social structure of a resident community of free-ranging Atlantic spotted dolphins Stenella frontalis. Foraging behaviors of juvenile dolphins were analyzed in 24 independent foraging events recorded on video from 1994 to 2013. Forty-nine juveniles in total were observed, including eight individually identified juveniles foraging alone, eight individually identified juveniles foraging in pairs, and 33 juveniles foraging in eight subgroups of three or more dolphins. The comparison of older juveniles' behavior against younger juveniles' behavior in juvenile play-forage subgroups suggested the potential for horizontal transmission of information about prey location. However, we found no direct evidence for social learning or of teaching in pairs. This new information about wild Atlantic spotted dolphin social structure is a starting point in horizontal information transmission research and is important in terms of cognitive processes and welfare implications.
\end{abstract}

Keywords - Atlantic spotted dolphins, Juvenile, Social learning, Horizontal transmission

In animal societies, social structure and social interactions influence the direction of information transmission within a group (Coussi-Korbel \& Fragaszy, 1995). The term 'vertical transmission' refers to information transmission between generations, for example, piglets learning about foraging from the mother (Oostindjer et al., 2011). The term 'horizontal transmission', however, is used to describe information transmission within generations and between individuals of the same age, for example, domestic hens influencing food preferences of observing hens by providing visual clues (Sherwin, Heyes, \& Nicol, 2002). Sometimes, the spread of novel behaviors within groups can contribute to the diffusion of maladaptive foraging behaviors, for example, when dogs prefer to use a less adaptive behavior gained from observing a demonstrator (Pongrácz, Miklósi, Kubinyi, Topál, \& Csányi, 2003). However, horizontal information transmission has many benefits and is likely to be adaptive when transmitted 
information is of transient value; for example, when different foraging strategies are used following temporary local variations in the environment (Laland, Richerson, \& Boyd, 1996).

In a cetacean society, social information can be transmitted vertically and horizontally (Herzing, 2005). In a Bahamian community of free-ranging Atlantic spotted dolphins, Stenella frontalis, sexually mature females have a calf every three and a half years on average with a subsequent juvenile period of approximately three years (Elliser \& Herzing, 2014; Herzing, 1997). During the juvenile period, the mother teaches the calf how to fish, and, by the time weaning occurs, the calf has become an independent forager partly as a result of vertical transmission (Bender, Herzing, \& Bjorklund, 2009).

Horizontal transmission was observed among juvenile dolphins in both interactive and noninteractive situations (Herzing, 2005). In this dolphin community, calves become independent at three or four years old, a year marked by a reduction in nursing, an increase in time spent alone and in time spent foraging in proximity of conspecifics other than the mother, including in juvenile play-forage subgroups (Miles \& Herzing, 2003).

Whereas vertical transmission contributes to the development of calves' foraging behavior (Bender et al., 2009), young dolphins' acquired foraging skills may vary at weaning. Yet, in order to survive, dolphins must become competent foragers irrespective of the length and the skills acquired by the end of the nursing period. Whether, and how, horizontal transmission of social information between juvenile dolphins may contribute to the development of foraging skills in young juveniles is currently poorly understood. Therefore, the aim of the present study is to characterize horizontal transmission, and identify potential underlying social-cognitive mechanisms thereof in the free-ranging Bahamian community of Atlantic spotted dolphins.

Every individual has a role in its social network (Lusseau \& Newman, 2004). One of the ways one can explore and understand the mental mechanisms underlying animals' perception, processing, and transmission of information is by measuring the model's and the learner's behavior (Herman, 1980; Herzing, 2006). The social-cognitive mechanisms by which animals learn individually and from one another have been widely studied (Heyes \& Galef, 1996). An animal can make use of the experience of a conspecific by acquiring information and new behaviors through relatively simple cognitive processing or via more sophisticated cognitive processes (Galef \& Giraldeau, 2001). An observing animal can be subject to social influence by simply being in the same environment as a demonstrator through exposure (Whiten \& Ham, 1992). The presence of a demonstrator can also simply affect an observer's motivation through social enhancement (Hoppitt \& Laland, 2008; Visalberghi, 1987; Whiten \& Ham, 1992), and it can direct an observer's attention to parts of the environment that were not previously noticed through local enhancement (Galef \& Giraldeau, 2001; Hoppitt \& Laland, 2008). Equally, a demonstrator's behavior can direct an observer's attention towards an object, irrespective of where the object is subsequently located through stimulus enhancement (Heyes, 1994; Palameta \& Lefebvre, 1985; Whiten \& Ham, 1992).

Greater cognitive mechanisms give rise to social learning, defined as the acquisition of knowledge of skills, by indirect observation or interaction with a conspecific (Nicol, 2006). Social learning is differentiated from enhancement mechanisms described above, as in all social learning cases, the model's influence on the learner results in the learner learning as a result of experiencing the social situation (Galef \& Laland, 2005; Nicol, 2006; Whiten, 2000). Social learning mechanisms include imitation (Whiten \& Ham, 1992; Whiten, Horner, Litchfield, \& Marshall-Pescini, 2004; Zentall, 2003), goal emulation (e.g., Tomasello, Davis-Dasilva, Camak, \& Bard, 1987) and observational conditioning (e.g., Mineka \& Cook, 1988; Tanida \& Nagano, 1998). Social learning provides an alternative of reduced costs for the learner to individual associative learning (e.g., trial-and-error learning), while offering a way to continue developing adaptive behavior from the presence of others (Nicol, 1995). Teaching is another form of social learning, and is defined as guided instruction, as a modification of the teacher's behavior at a cost to the teacher in the presence of naïve observers, according to the definition proposed by Caro and Hauser (1992).

Cognitive processes in animals have been extensively studied in several primate species (Tomasello \& Call, 1997; Whiten \& Ham, 1992), yet most literature on cetacean cognition comes from 
studies on bottlenose dolphins (Tursiops truncatus) kept in laboratory environments (Herman, 2010). Furthermore, research on social-cognitive processes in wild populations may be slow due to the kind of data collection necessary for the analysis of behavior. Laboratory studies show that dolphins understand basic grammatical structure and aspects of semantic reference in the learning of an artificial language (Herman, Kuczaj, \& Holder1993; Herman, Richards, \& Wolz, 1984; Mercado, Uyeyama, Pack, \& Herman, 1999). Dolphins also memorize and remember sounds and actions (Herman \& Gordon, 1974; Thompson \& Herman, 1977, 1981) and questions about the extent to which dolphins are self-aware continue to be debated (Harley, 2013; Reiss \& Marino, 2001), but they can understand symbolic references to their own different body parts (Herman, Matus, Herman, Ivancic, \& Pack., 2001) and are able to utilize pointing gestures for referencing purposes (Herman et al., 1999; Xitco, Gory, \& Kuczaj, 2004). Such skills may underlie a dolphin's ability to synchronize known and novel behaviors (Pack \& Herman, 2006).

Existing long-term datasets have facilitated research on social-cognitive processes in wild populations and the exploration of detailed underwater behavior of free-ranging cetaceans. In settings where natural behaviors are expressed and social-cognitive abilities can be tested, behavioral studies suggest that dolphins tackle environmental challenges and manage complex social lives using advanced cognitive skills (Emery \& Clayton, 2004; Marino et al., 2007). In fact, the dolphin brain may have evolved to its current size in response to multiple social requirements of living in a complex society, such as being able to communicate, collaborate and compete among individuals (Connor, 2007; Connor, Smolker, \& Richards, 1992), and possibly also due to the development and use of echolocation (Jerison, 1986; Ridgeway, 1986; Wood \& Evans, 1980). Dolphins learn, use, and mimic signature whistles to call each other (Janik, 2000; Janik, Sayigh, \& Wells, 2006), organize synchronized and collaborative feeding (e.g., Duffy-Echevarria, Connor, \& St. Aubin, 2007), and may even teach foraging techniques (Bender et al., 2009; Rendell \& Whitehead, 2001) and tool-use (Krützen et al., 2005) to their offspring. Socialcognitive information transmission mechanisms can take place between individuals among small groups, communities, and larger societies, while leading to information transmission at a cultural level (Franz \& Matthews, 2010; Laland \& Janik, 2006; Norris \& Dohl, 1980; Whitehead \& Rendell, 2015). Horizontal transmission could facilitate the continuing development of foraging behavior in young dolphins by allowing young dolphins to develop their potential from interaction with more competent models, resulting in a steady state of behavioral development where young juveniles have reached the foraging competency required for survival (Kuczaj, Paulos, Ramos, 2005). The structure of a marine mammal society is complex and responds to a variety of factors, including human activity (Ansmann, Parra, Chilvers, \& Lanyon, 2012; Chilvers \& Corkeron, 2001; Chilvers, Corkeron, \& Puotinen, 2003; Elliser \& Herzing, 2014; Mann \& Watsoncapps, 2005). Understanding social-cognitive processes occurring within the social structure is important from a cognitive, welfare, educational, and evolutionary perspective (Mendl \& Paul, 2004). Cognitive development and social structure are crucial to the perpetuation of survival skills (Snyder et al., 1996; Whitehead, Rendell, Osborne, \& Würsig, 2004) and better understanding can contribute to the improvement of housing, management, and handling of captive and rescued animals (Barber, 2009; Jiang, Lück, \& Parsons, 2007; Wechsler \& Lea, 2007). In stranded dolphins being rehabilitated, the ability to catch live prey independently is one of many criteria that must be met in order to determine whether a rescued animal is fit for release (Barnett, 2002). Knowledge about the social-cognitive mechanisms underlying foraging behavior development in free-ranging populations is thus key to maximize the rate of successful rescue and rehabilitation of stranded animals. It may also shed light on unidentified evolutionary advantages of social information transmission.

The objectives of this study were to research horizontal information transmission through socialcognitive mechanisms among free-ranging juvenile Atlantic spotted dolphins. Horizontal information transmission among juvenile Atlantic spotted dolphins may occur in the following contexts: 1) through play-forage sequences of interactive juvenile subgroups, for example, via repetition of body movements by older juveniles towards a location, object or individual worthy of attention, or by older juveniles initiating a foraging behavior; and 2) through foraging performances in pairs, for example via noticeably different foraging performance duration by old juveniles when foraging in the presence of a young 
dolphin. Information transfer may occur via social learning by less experienced juveniles, where the younger juveniles benefit from observing their conspecifics' foraging experience; and possibly through demonstration by experienced juveniles, where the instructor's foraging behavior changes in the presence of naïve observers (Heyes, 1994). A set of 24 video sequences was analyzed to test for the presence of horizontal information transmission firstly in play-forage subgroups (Study One), and secondly, in pairs (Study Two), with a focus on behavioral modifications in older juveniles. The primary hypothesis was that older juveniles contribute to the further development of young dolphins' foraging performance, through social learning processes facilitated by behavioral modifications of more experienced juveniles.

\section{Study One}

Study One (Subgroups) tested the hypothesis that play-forage juvenile subgroups provide a platform for horizontal social information transmission through social-cognitive processes.

\section{Method}

\section{Study Site, Dolphin Community and Subjects}

The community of free-ranging Atlantic spotted dolphins on Little Bahama Bank (LBB) in the Bahamas has been observed every summer since 1985 for $4-5$ months. LBB is a shallow sandbank with waters 6 to $16 \mathrm{~m}$ deep, surrounded by steep drop offs into the $500 \mathrm{~m}$ deep waters of the Gulfstream. The location has extensive underwater visibility for observations and the study area covers approximately 500 $\mathrm{km}^{2}$ north of Grand Bahama Island. The bottom is primarily sandy, with zones of rock, reef and patches of seagrass (Thalassia testudimum). The life history, including non-invasive genetic analysis, (Elliser \& Herzing, 2012, 2013, 2016a, 2016b; Green, Herzing \& Baldwin, 2007, 2011) and the development and use of social and acoustic behaviors of this community of Atlantic spotted dolphins have been documented extensively (Au \& Herzing, 2003; Herzing, 2000, 2004, 2005; Herzing \& Brunnick, 1997; Herzing \& dos Santos, 2004; Herzing \& Elliser, 2013; Herzing \& Johnson, 1997; Herzing, Moewe \& Brunnick, 2003; Lammers, Au \& Herzing, 2003; Miles \& Herzing, 2003; Welsh \& Herzing, 2008).

The community includes approximately 100 individuals on any given year, although up to 330 have been identified over the decades (Elliser \& Herzing, 2014). Age class coloration is modified relative to that described for pantropical spotted dolphin Stenella attenuata (Perrin, 1970), with four consecutive developmental color classes identified for increasing levels of age-related skin pigmentation: two-tone, speckled, mottled and fused (Herzing, 1997). Both studies contained individuals of the two earliest age classes: the two-tone phase (neonates and calves, $\leq 4$ yrs) and the speckled phase $(4-9$ yr-old independent juveniles), with a large majority of dolphins belonging to the second earliest age class (due to juvenile subgroup analysis) and with the exception of one individual who belonged to the mottled phase (young adult, between 10 and 16 years old). Two-tone calves are grey-white and spotless. Speckled juveniles have at least two black spots on the ventral surface and several light grey spots on the dorsal surface. Before the speckled phase, the dolphins depend on their mother for survival; by the end of the speckled phase, dolphins move into their young adult stage (Herzing, 1997). Underwater footage was selected for the presence of benthic foraging behavior (Figure 1). Location of the prey was identifiable in most video recordings and when not, prey location was determined according to marks in the sand and dolphin body movements.

\section{Materials}

\section{Data Collection}

Video and audio sequences recorded by Wild Dolphin Project researchers using various types of underwater cameras with attached hydrophone during summer field seasons from years 1994 to 2013 were extracted from the Wild Dolphin Project database for this study. 


\section{Experimental Treatments and Video Standardization}

A play-forage juvenile subgroup was defined as a group of three to five juveniles that+ display foraging behavior while socially interacting and swimming together at the bottom of the sea. The relative age of the juveniles in each group is visibly distinguishable via skin pigmentation and/or body size in cases where individual identification was unavailable. A benthic foraging sequence in juvenile subgroup was defined as the period between the start and the end of a benthic-feeding event in subgroup. The sequence starts when an individual initiates scan, dig or chase. The sequence ends when one of the following cases occurred: fish chase is over because fish escapes or is ingested, subgroup dissolves or subgroup leaves benthic area. The videos $(n=8)$ were selected for the presence of foraging juveniles and were included in the analysis as long as the focal juveniles did not go out of the video for more than three seconds in play-forage subgroups.

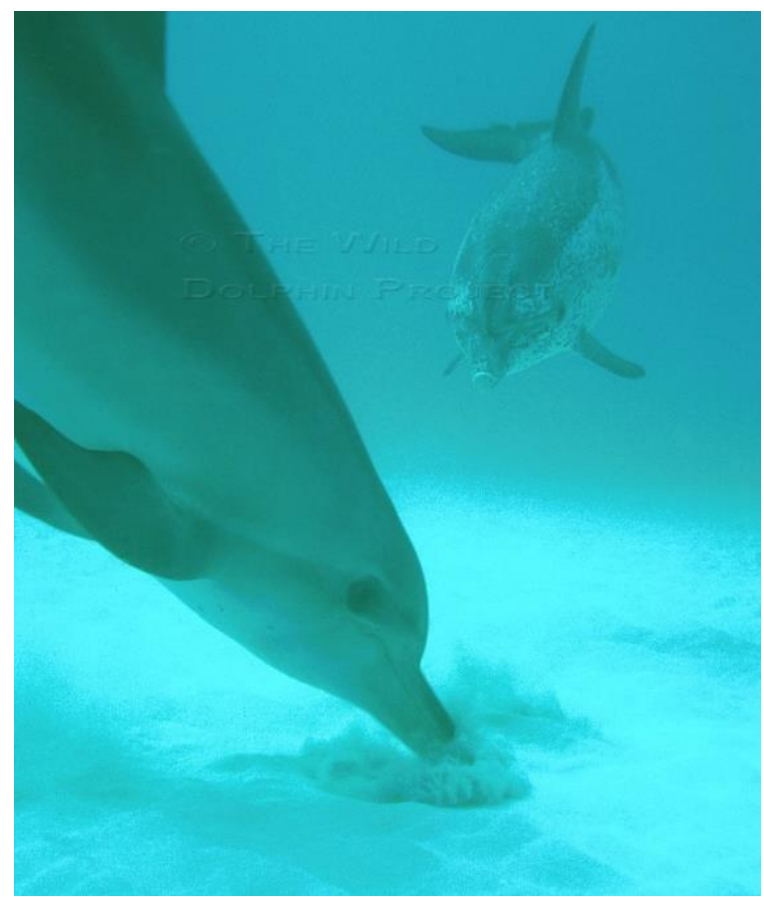

Figure 1. A spotless two-tone calf digs in the sand for fish while being watched by an elder dolphin. Credit: Wild Dolphin Project

\section{Procedure}

\section{Behavioral Definitions}

Benthic foraging was defined as searching and eating benthic fish such as flounder (family Bothidae), snakefish (family Synodontidae) and razorfish (family Clinidae). A foraging bout was divided into four distinct phases: scan for the prey, dig the prey out of the sand, chase the prey and ingest the prey (Bender et al., 2009). The benthic foraging behaviors were recorded as described in Table 1.

\section{Video Analysis, Type of Scoring and Method of Recording}

One observer, the first author, compared the behavior of older juveniles versus young dolphins within eight play-forage juvenile subgroups (2.22 min of footage in total, involving 33 dolphins) scoring for seven benthic foraging behaviors, during eight independent benthic foraging sequences. The relative age of each juvenile in each group was visibly distinguishable via skin pigmentation and/or body size. When available, juvenile identity was determined using data from the Wild Dolphin Project preliminary 
video $\log$ and visible body marks. The video sequences were watched in a randomized order using QuickTime Player. Each juvenile of a subgroup was monitored throughout the benthic foraging sequence and was given an age category. The youngest and (when applicable) the second youngest individuals of the subgroup were merged in the young category, while the oldest (and when applicable) the second and third oldest individuals of the subgroup were merged in the old category. The observer scored for seven behaviors (scan, dig, chase, prey-focus, prey-turn, peer-focus and peer-turn) as events: each event scored in a category of foraging behavior and body-orienting movement (described in Table 1). The four bodyorienting movements (peer-focus, prey-focus, peer-turn and prey-turn) were merged in two movement categories. Prey-focus and prey-turn were merged into the prey-directed movements category, while peerfocus and peer-turn were merged into the peer-directed movements category. The observer applied modifiers (initiate and follow) to the analysis of scan, dig and chase in juvenile subgroups. The data collected were categorical.

Table 1

Ethogram of Benthic Foraging Behaviors in Subgroups

\begin{tabular}{|c|c|c|}
\hline Foraging Behavior & Definition & Modifier * \\
\hline \multirow{2}{*}{ Scan } & \multirow[t]{2}{*}{$\begin{array}{l}\text { The dolphin repeatedly moves its head horizontally or vertically } \\
\text { while swimming by the sea floor, using buzz sounds at times }\end{array}$} & Initiate $^{1}$ \\
\hline & & Follow $^{2}$ \\
\hline \multirow{2}{*}{ Dig } & \multirow[t]{2}{*}{$\begin{array}{l}\text { The dolphin introduces its rostrum into the sand, leading to exposure } \\
\text { of the prey. The body is most often oriented vertically or obliquely } \\
\text { with the rostrum in contact with the sand and oscillating up, down } \\
\text { and sideways }\end{array}$} & Initiate \\
\hline & & Follow \\
\hline \multirow{2}{*}{ Chase } & $\begin{array}{l}\text { The dolphin swims closely behind the benthic fish (after the fish } \\
\text { being dug up) - usually occurs prior to catching the fish with the } \\
\text { mouth }\end{array}$ & Initiate \\
\hline & & Follow \\
\hline \multicolumn{2}{|c|}{ Body-orienting movements (BOM) } & $\begin{array}{c}\text { Category } \\
\text { (and name) } \\
\text { of } \\
\text { BOM }\end{array}$ \\
\hline \multirow{2}{*}{ Focus } & $\begin{array}{l}\text { After the prey is dug out of the sand, the dolphin's body position } \\
\text { remains oriented towards the prey, with the rostrum directly pointing } \\
\text { at the fish and with a distance of half a body length from the prey }\end{array}$ & $\begin{array}{l}\text { Prey-directed } \\
\text { movement (prey- } \\
\text { focus) }\end{array}$ \\
\hline & $\begin{array}{l}\text { The dolphin body position is oriented towards its peer with the } \\
\text { rostrum directly pointing at the peer and with a distance of half a } \\
\text { body length from the peer }\end{array}$ & $\begin{array}{l}\text { Peer-directed } \\
\text { movement (peer- } \\
\text { focus) }\end{array}$ \\
\hline \multirow[t]{2}{*}{ Turn } & $\begin{array}{l}\text { The dolphin reorients its body position so as to follow a prey closely } \\
\text { by turning sharply and effecting a rotation from } 45^{\circ} \text { to } 360^{\circ} / \text { complete } \\
\text { turnaround. This results in the dolphin's body axis parallel to the fish } \\
\text { body axis and the dolphin is located within a radius of at minimum } \\
\text { half a body length of the prey (or closer) }\end{array}$ & $\begin{array}{l}\text { Prey-directed } \\
\text { movement (prey- } \\
\text { turn) }\end{array}$ \\
\hline & As for prey turn, but oriented towards peer & $\begin{array}{l}\text { Peer-directed } \\
\text { movement (peer } \\
\text { turn) }\end{array}$ \\
\hline \multicolumn{3}{|l|}{ * Modifiers } \\
\hline${ }^{1}$ Initiate & \multicolumn{2}{|c|}{$\begin{array}{l}\text { A dolphin initiates a foraging behavior in a social subgroup when it begins performing scan, dig or } \\
\text { chase. }\end{array}$} \\
\hline${ }^{2}$ Follow & \multicolumn{2}{|c|}{$\begin{array}{l}\text { A dolphin follows when it starts performing the same foraging behavior as the one any peer previously } \\
\text { started performing. A foraging behavior was no longer considered as followed if five seconds or more } \\
\text { had elapsed since the behavior was initiated. }\end{array}$} \\
\hline
\end{tabular}




\section{Statistical Analysis}

With the categorical data obtained from play-forage subgroup analysis, we tested for association between age category and the focus of body-orienting movements (prey/peer) using a chi-square test. A second chi-square test (for association between age category and prey-directed movements, prey-focus and prey-turn), and a third chi-square test (for association between age category and peer-directed movements, peer-focus and peer-turn) were carried out. Finally, a Fisher's exact test for association was carried out between age category (young/old) and behavior modifier (initiate/follow).

\section{Results}

For inter-observer reliability, one independent observer scored two videos of each treatment group ( $25 \%$ of the videos, $n=2$ ). There was a significant correlation between the observations by the first author and the independent observer $\left(r^{2}=0.93\right)$.

\section{Comparison of Foraging Behavior of Old versus Young Juveniles in Juvenile Subgroup}

The duration of a benthic foraging sequence in juvenile subgroups was 10 to $37 \mathrm{~s}(M=19.3 ; S E=$ 4.37). First, a chi-square analysis showed that, whereas there was no effect of point of focus (peer or prey) for younger juveniles, there was a significant effect for older juveniles with older juveniles looking more at the prey than peers: there was an association between age and the point of focus prey for both body-orienting movements (focus and turn), with the total count of focus and turn showing that older juveniles performed more prey-directed movements than peer-directed movements $\left(\chi^{2}(1)=4.96, p=\right.$ $0.03, N=64)$, thereby focusing significantly more on the prey than on their companions. Additional chisquare tests showed that there was no effect of body-orienting movement type (focus or turn) for younger juveniles or older juveniles, i.e., there was no significant difference between the number of focus or turn performed by younger and older juveniles. Respectively, older juveniles performed 22 prey-directed movements of which 13 were prey-focus and nine were prey-turn $\left(\chi^{2}(1)=1.303, p=0.249, N=39\right)$, while only performing seven peer-directed movements of which six were peer-focus and one was peerturn $\left(\chi^{2}(1)=0.503, p=0.462, N=25\right)$. In comparison, young juveniles performed 17 prey-directed movements and 18 peer-directed movements. The data presented in Table 2 show the distribution of body-orienting movements by older juveniles per point of focus.

Table 2

Data Showing Association Between Body-orienting Movements and Points of Focus Performed by Old Juveniles in Social Playforage Subgroups.

\begin{tabular}{lccc}
\hline $\begin{array}{l}\text { Category of body-orienting } \\
\text { movements }\end{array}$ & Focus & Turn & Total \\
\hline Prey-directed movement & 13 & 9 & $22^{*}$ \\
Peer-directed movement & 6 & 1 & 7 \\
\hline
\end{tabular}

Note. Pearson's chi-squared statistic $\chi^{2}$, degree of freedom, p value $(p)$ and total count $(N)$ in previous paragraph.

The Fisher's exact test showed that there was no association between age category (young/old) and behavior modifier (initiate/follow). The relationships between age and modifier were not significant (scan: $p=0.32$; dig: $p=0.62$; and chase: $p=0.27$ ). Older juveniles were not more likely to initiate the performance of any foraging behavior, and young juveniles were not more likely to follow foraging behaviors previously performed. 


\section{Study Two}

Study Two (Alone versus in Pairs) tested the hypothesis that older juveniles modify their behavior in the presence of a young dolphin (young juvenile or calf) during a standardized foraging event.

\section{Method}

Study site, dolphin community, subjects and data collection were as in Study One.

\section{Materials}

\section{Experimental treatments and video standardization}

A juvenile foraging alone was defined as a foraging sequence in which the juvenile forages exclusively alone, without physical or social interaction with other dolphins; no dolphin gets closer than two body-lengths of the subject throughout the foraging event. Juveniles foraging in pairs were defined as a foraging sequence during which one pair of juveniles forage together; where an older juvenile forages in the presence of a calf or young juvenile. The two-tone calf or the young juvenile are always visibly smaller than the old speckled juvenile via skin pigmentation and body size. This type of sequence includes some level of physical and social interaction. A complete foraging sequence was defined as the period between the start and the end of the benthic feeding event. A sequence starts when the dolphin begins to scan the bottom using echolocation, accompanied by buzz sounds at times, and makes scanning horizontal head movements. A sequence ends when one of the following cases occurs: fish gets away, fish is ingested, dolphin swims upwards from the bottom so the head is higher than the fluke while moving for three seconds, or the dolphin moves at least one body length away from the sea floor. The videos $(n=16)$ were included in the analysis as long as the focal juveniles did not disappear from the frame of the video for more than five seconds when foraging alone and in pairs.

\section{Procedure}

\section{Behavioral Definitions}

Study Two compared scan, dig and chase exclusively in juveniles foraging alone versus in pairs. Scan, dig and chase were defined as in Study One (Table 1).

\section{Video Analysis, Type of Scoring, and Method of Recording}

To ensure independence of the samples within and across the two treatment groups, one observer, the first author, determined the identity of 19 dolphins (including all eight juveniles foraging alone and all eight older juveniles foraging in pairs) out of the 24 dolphins involved in the video selection, including age and gender, using data from the Wild Dolphin Project preliminary video log and visible body marks. The video sequences were watched in a randomized order, using QuickTime Player. The duration of the complete foraging sequence and the duration of each foraging behavior performed by juveniles alone and the older juvenile of each pair were recorded continuously using a stopwatch. The observer compared the duration of three foraging states (scan, dig and chase as defined in Table 1) of eight juveniles foraging alone (total of $4.96 \mathrm{~min}$ ) versus eight old juveniles foraging in pairs (total of $3.68 \mathrm{~min}$ ) during distinct complete foraging sequences $(n=16)$. The observations were scored as states: the behaviors were measured in duration, i.e., the time during which a specific foraging behavior continues. The data collected for foraging state were continuous (in seconds). 


\section{Data Handling and Statistical Analysis}

Raw data were transformed to obtain the percentage of time spent performing each type of feeding behavior during a complete foraging sequence. Our two sets of percentage data collected from complete foraging sequences were independent and continuous. An Anderson-Darling normality test was used and found to be non-normal (see Results) and therefore a Kruskal-Wallis test was used to test for difference in the mean percentage of time spent performing foraging behaviors between Alone and Pairs. Minitab 17.1.0 was used for all statistical analysis.

\section{Analysis of the Relationships Between Foraging Behaviors}

For further investigation into the relationship between the variables across the whole juvenile population, a Spearman's correlation test was used on the 16 juvenile dolphins (the eight Alone and the eight older juveniles in Pairs) recorded. These tests were performed on the whole dataset to understand how foraging behaviors related to one another when juveniles foraged in pairs.

\section{Results}

Inter-observer reliability was assessed as in Study One with one independent observer scoring two videos of each treatment group ( $25 \%$ of the videos, $n=4)$. There was a significant correlation between the observations by the first author and the independent observer $\left(r^{2}=0.98\right)$.

\section{Comparison of Juvenile Behavior Foraging Alone versus in Pairs}

The duration of foraging states in pairs ranged from $0 \mathrm{~s}$ (when a foraging behavior was not performed $)$ to $27.8 \mathrm{~s}(M=6.72 ; S E=1.03)$. An Anderson-Darling normality test revealed that percentage of scan and chase in pairs and percentage of dig alone were normal (respectively, $p=0.15 ; p=0.13$; and $p=0.6$ ); however, percentage of scan and chase alone and percentage of dig in pairs were non-normal (respectively, $p=0.03 ; p<0.005$; and $p=0.05$ ).

There was no significant difference in the percentage of time spent scanning, digging and chasing between the two treatment groups. The Kruskal-Wallis test results are included in Figure 2. The subjects from the Alone and Pair treatments spent a similar amount of time scanning. Digging was the foraging behavior performed the longest by juveniles foraging alone. There was a trend for the older juveniles in pairs to spend less time digging but it was not statistically significant. Chasing had the shortest duration of all foraging behaviors performed.

\section{Relationships Between Foraging Behaviors}

There was a significant positive relationship with a moderate level of association between digging and chasing within individuals, as shown by the Spearman rank correlation results presented in Table 3. We also found a significant negative relationship with a moderate level of association between scanning and digging, and a significant negative relationship with a moderate level of association between scanning and chasing. 


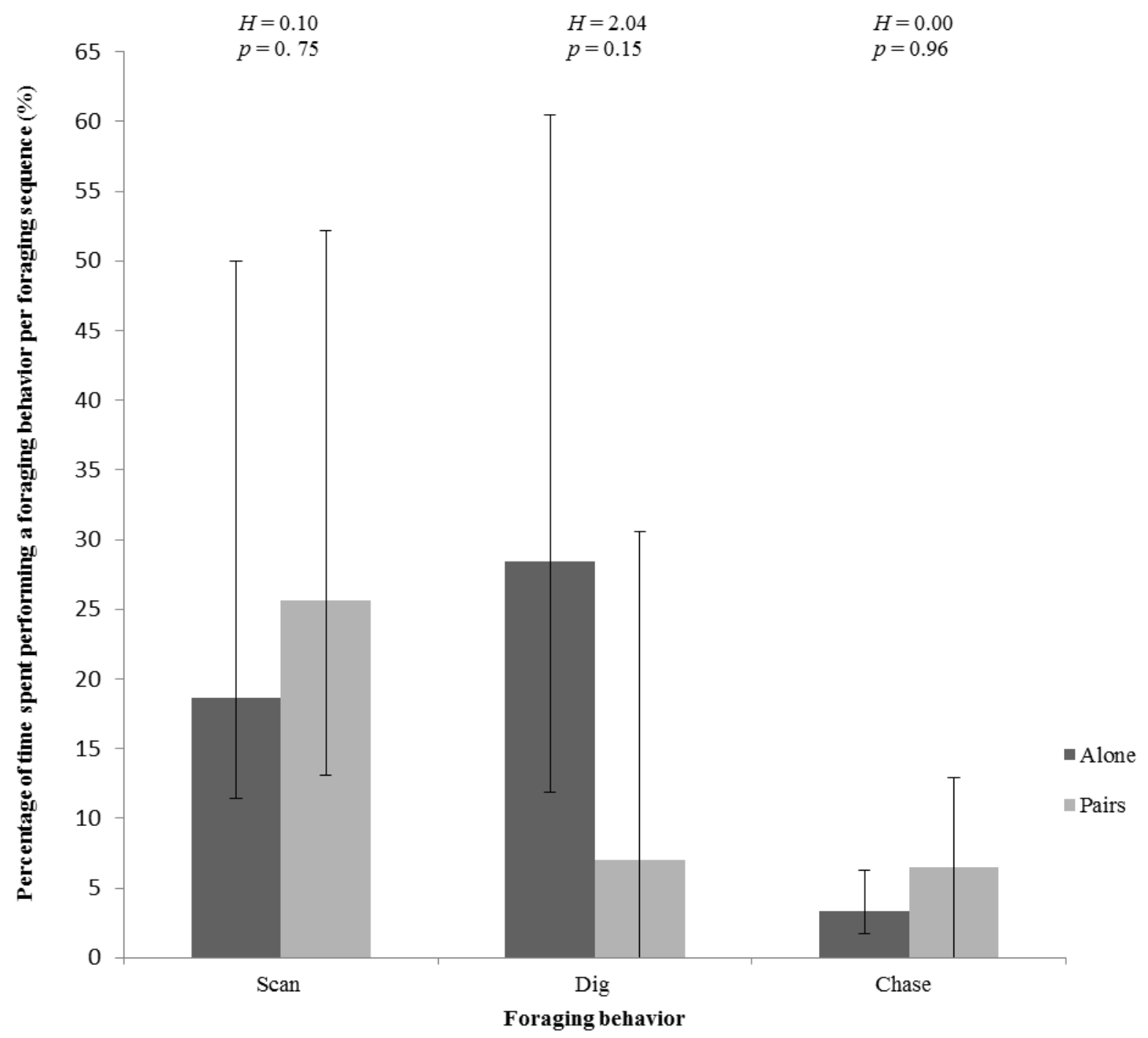

Figure 2. Median percentage of time spent scanning, digging and chasing per complete foraging sequence between the Alone and Pairs (older juvenile). Median with interquartile range and Kruskal-Wallis test results (t statistic $(H)$ and $\mathrm{p}$ value $(p)$ above the corresponding foraging behavior.

Table 3

Correlation Matrix of Spearman rho Values $\left(r_{S}\right)$ and $p$ Values $(p)$ for Foraging Behaviors Performed by all Subjects in the Alone and Pairs (older juvenile) $(n=16)$ During a Complete Foraging Sequence.

\begin{tabular}{lll}
\hline & Scan & Dig \\
\hline Dig & $r_{S}=-0.564$ & \\
& $\begin{array}{l}p=0.02 \\
\\
\end{array}$ & \\
\hline Chase & $r_{S}=-0.573$ & $r_{S}=0.549$ \\
& $p=0.02$ & $p=0.03$ \\
& $*$ & $*$ \\
\hline
\end{tabular}

Note. ${ }^{*}$ indicates significant results. 


\section{Discussion}

Results of the present study suggest that horizontal information transmission is possible within play-forage juvenile dolphin subgroups. In social subgroups, older juveniles performed significantly more prey-oriented movements than peer-oriented movements, compared to young dolphins. The significant repetition of body-orienting movements of the older dolphins focused on the prey rather than on their companions. Older juveniles enhanced prey location information by turning their head (prey focus) and body (prey turn) towards the benthic fish, thereby providing visual cues for prey detection to young dolphins. However, we found no evidence for teaching per se of foraging behaviors in subgroups, or in pairs. First, older juveniles did not initiate foraging behaviors nor did younger juveniles follow the foraging behaviors of older juveniles in subgroups (Study One). Second, older juveniles did not alter their scanning, digging and chasing time in presence of young dolphins during a complete foraging sequence (Study Two). The correlation test outlined that juvenile dolphins tend to perform digging and chasing together; two active behaviors used for feeding purposes that result in the ingestion of the prey, unlike scanning, which involves the use of echolocation at times that is used for exploratory purposes and preyfinding in the context of foraging.

The results of Study One (Subgroups) identified one significant difference in the behavior of older juveniles with regards to prey. However, the data collected on the initiation and following of foraging behaviors showed no evidence for teaching of foraging behaviors in subgroups, i.e., older juveniles did not initiate foraging behaviors, and younger juveniles did not follow them, and Study Two (Alone versus Pairs) suggests that older juveniles do not modify foraging performance time in presence of a younger dolphin. The implications of our study therefore suggest that horizontal transmission is present, with social information transfer possibly occurring through social enhancement and social learning, but not to the extent where older juveniles teach, per se, foraging to younger juveniles. Challenging to identify in wild populations (Thornton \& Raihani, 2010), teaching would allow young juveniles to acquire foraging skills more rapidly (Caro \& Hauser, 1992). An analogy to social situations where young chimpanzees received less attention than same-age and older individuals in social subgroups (Biro et al., 2003) may be drawn with juvenile subgroups of Atlantic spotted dolphins, as older juveniles focused on the prey and they did not demonstrate foraging to the younger juveniles in social subgroups.

At this stage, our study remains inconclusive regarding the possible occurring social learning mechanisms, due to small sample size and inability to manipulate behaviors and conditions. A larger sample size of our standardized footage for the analysis of juveniles foraging in pairs might have increased the power of efficiency of the Kruskal-Wallis tests, and reduced the variability of results in Figure 2. Future research is necessary to characterize possible social learning mechanisms in juvenile dolphins' play-forage subgroups, to determine what effect the repeated body-orienting movements performed by the older juveniles have on young dolphins' learning, and to what extent such an effect affects young dolphins' foraging competence. Many avenues demand to be explored for the potential social-cognitive processes underlying horizontal transmission to be identified. Social cognitive processes, such as social enhancement (e.g., exposure) and social learning (e.g., imitation and goal emulation) may underpin horizontal transmission among juvenile subgroups but it is not yet understood which exactly, and how. Exposure may occur, for juvenile play-forage subgroups constitute a favorable environment for social enhancement and older juveniles' behavior provide visual cues. Stimulus enhancement may be present: the focus of older, and supposedly more experienced, juveniles on the prey may help observing young juveniles to detect, pinpoint and identify fish more rapidly while limiting unnecessary exploration, as is the case among certain avians with grains (Nicol \& Pope, 1994, 1999; Palameta \& Lefebvre, 1985). It may be that, through goal emulation, the young juveniles benefit from opportunities to associate preyorienting behavior with a successful outcome (success being the ingestion of food) when seeing older juveniles directing attention towards the fish and eating it, i.e., young dolphins may emulate the goal behind prey focus and prey turn performances (Yeater \& Kuczaj, 2010). The potential for presence of stimulus enhancement and goal emulation mechanisms in Atlantic spotted dolphin society seem 
analogous to the social learning mechanisms evoked in young primates (Tomasello et al., 1987; Whiten, 2000), despite different physical environments. Young dolphins may also learn by imitation and by observational conditioning despite the highly social and playful foraging context.

Benthic foraging sequences in juvenile subgroups are highly social contexts in which sonorous interaction, play and possibly some level of competition can occur at the same time. Examples for future questions could include: when do old juveniles perform more prey-orienting movement: in social subgroups, in pairs or alone; are there differences between young dolphins' behavior as a function of presence or time spent with older juveniles in the play-forage subgroup? Further, the trend of older juveniles to spend less time digging in pairs was non-significant but suggestive, and therefore worthy of additional study. It may also be that older juveniles' repeated prey-oriented movements in play-forage subgroups are part of horizontal transmission processes that are associated with social aspects not tested for, such as, acoustic communication development.

Whereas age influenced the frequency of body-orienting movements in juvenile subgroups, gender, personality, novelty of behavior and environmental context are likely to have intervened in horizontal information transmission as well (Kuczaj, Yeater, \& Highfill, 2012; Laland, 2004; Wilson, Clark, Clark, Coleman, \& Dearstyne, 1994). Dolphins, like other animal species, develop and conserve various kinds of personality traits across time (Highfill \& Kuczaj, 2007). In captivity, both old and bold bottlenose calves are likely to be observed and imitated by young calves (Kuczaj, Makecha, Trone, Paulis, \& Ramos, 2006). Moreover, calves are prone to spontaneously produce as well as imitate novel behaviors, particularly novel play behaviors performed by other calves (Kuczaj \& Yeater, 2006). In the context of wild juvenile subgroups, young juveniles did not appear to reproduce per se familiar foraging behaviors, possibly because the subjects had already been taught scanning, digging and chasing by their mother in the same environmental context and were independent foragers (Bender et al., 2009). The kind of teaching provided by experienced adults before weaning is very important in foraging behavior development (Bender et al., 2009), but it is possible that simple cognitive processing suffices to allow young dolphins to gain information between themselves, as is the case for young wild chimpanzees foraging for termites (Lonsdorf, 2006). However, it may be that young juveniles chose a salient individual among the subgroup members according to criteria that our study did not measure (e.g., novelty of behavior, familiarity with the peer, personality), with any influence of the model on the young juvenile's behavior being due to factors not yet identified.

Foraging appears to be socially taught and learned in the Bahamian Atlantic spotted dolphin society (Bender et al., 2009) and prey information is possibly shared in the social community within juvenile subgroups through horizontal transmission. Competence as a forager is a developmental outcome that clearly benefits dolphins individually. If, as for cats (Bateson, 2015), we can assume that the level of overall foraging competence at adulthood has evened early individual variations in foraging skills, then young or less experienced dolphin calves catch up with adult foraging ability by the time they are fully grown. The formation of play-forage juvenile subgroups following the weaning period, by providing a platform for horizontal transmission, would support the continuing development of foraging behavior in spite of individuals having possibly different types of early experience with their mothers. Horizontal information transmission in juvenile subgroups could play a role in the preservation of the cultural benthic feeding traits in the Atlantic spotted dolphin culture, as a result of a complex process emerging from the relationships between young society members, while contributing to survival.

To conclude, our study identified foraging behaviors potentially involved with horizontal information transfer in juvenile play-forage subgroups in a free-ranging community of Atlantic spotted dolphins. Horizontal transmission in this context is suggestive of several types of underlying social enhancement and, social learning mechanisms. However, our study does not support teaching by older juveniles and remains inconclusive as to the extent to which young dolphin learning occurs. Our findings are important in terms of social-cognitive development, welfare, educational, and evolutionary implications for this wild Atlantic spotted dolphin community, and is a starting point in research into horizontal information transmission. Future research is needed to identify social information transmission 
mechanisms and to determine the extent of young dolphins' learning from older juvenile's repeated movements, and to what extent older juveniles influence juveniles' foraging competence.

\section{Acknowledgments}

Many thanks to the Wild Dolphin Project for sharing their long-term database for this study. Research for the study was conducted under a research permit from the Bahamian Department of Fisheries.

\section{References}

Ansmann, I. C., Parra, G. J., Chilvers, B. L., \& Lanyon, J. M. (2012). Dolphins restructure social system after reduction of commercial fisheries. Animal Behaviour, 84, $575-581$.

Au, W. W. L., \& Herzing, D. L. (2003). Echolocation signals of wild Atlantic spotted dolphin (Stenella frontalis). Journal of the Acoustical Society of America, 113, 598 - 604.

Barber, J.C. (2009). Programmatic approaches to assessing and improving animal welfare in zoos and aquariums. Zoo Biology, 28, $519-530$.

Barnett, J. (2002). Evaluation of rehabilitation as an option for stranded dolphins, porpoises and whales. (pp. 1 - 91). Retrieved from: http://www.bdmlr.org.uk/

Bateson, P. (2015). The domestic cat: the biology of its behaviour. Cambridge, UK: Cambridge University Press.

Bender, C. E., Herzing, D. L., \& Bjorklund, D. F. (2009). Evidence of teaching in Atlantic spotted dolphins (Stenella frontalis) by mother dolphins foraging in the presence of their calves. Animal Cognition, 12, 43 53.

Biro, D., Inoue-Nakamura, N., Tonooka, R., Yamakoshi, G., Sousa, C., \& Matsuzawa, T. (2003). Cultural innovation and transmission of tool use in wild chimpanzees: Evidence from field experiments. Animal Cognition, 6, $213-223$.

Caro, T. M., \& Hauser, M. D. (1992). Is there teaching in nonhuman animals? The Quarterly Review of Biology, 67, $151-174$.

Chilvers, B. L., \& Corkeron, P. J. (2001). Trawling and bottlenose dolphins' social structure. Proceedings of the Royal Society: Biological Sciences, 268, $1901-1905$.

Chilvers, B. L., Corkeron, P. J., \& Puotinen, M. L. (2003). Influence of trawling on the behaviour and spatial distribution of Indo-Pacific bottlenose dolphins (Tursiops aduncus) in Moreton Bay, Australia. Canadian Journal of Zoology, 81, 1947 - 1955.

Connor, R. C. (2007). Complex alliance relationships in bottlenose dolphins and a consideration of selective environments for extreme brain size evolution in mammals. Philosophical Transactions of the Royal Society of London B: Biological Sciences, 362, $587-602$.

Connor, R. C., Smolker, R. A., \& Richards, A. F. (1992). Dolphin alliances and coalitions. In A. H. Harcourt, \& F. B. de Waal (Eds), Coalitions and alliances in human and other animals (pp. 415 - 443). Oxford, UK: Oxford University Press.

Coussi-Korbel, S., \& Fragaszy, D. M. (1995). On the relation between social dynamics and social learning. Animal Behaviour, 50, 1441 - 1443.

Duffy-Echevarria, E. E., Connor, R. C., \& St. Aubin, D. J. (2007). Observations of strand-feeding behavior by bottlenose dolphins (Tursiops truncatus) in Bull Creek, South Carolina. Marine Mammal Science, 24, 202 $-206$.

Elliser C. R., \& Herzing, D. L. (2012). Community structure and cluster definition of Atlantic spotted dolphins, Stenella frontalis, in the Bahamas. Marine Mammal Science, 28, e486 - e502.

Elliser C. R., \& Herzing, D. L. (2013). Social structure of Atlantic spotted dolphins, Stenella frontalis, following environmental disturbance and demographic changes. Marine Mammal Science, 30, 329 - 347.

Elliser, C. R., \& Herzing, D. L. (2014). Long-term social structure of a resident community of Atlantic spotted dolphins, Stenella frontalis, in the Bahamas 1991-2002. Marine Mammal Science, 30, 308 - 328.

Elliser C. R., \& Herzing, D. L. (2016a). Long-term interspecies association patterns of Atlantic bottlenose dolphins, Tursiops truncatus, and Atlantic spotted dolphins, Stenella frontalis, in the Bahamas. Marine Mammal Science, 32, $38-56$.

Elliser C. R., \& Herzing, D. L., (2016b). Changes in interspecies association patterns of Atlantic bottlenose dolphins, Tursiops truncatus, and Atlantic spotted dolphins, Stenella frontalis, after demographic changes related to environmental disturbance. Marine Mammal Science, 32, 602-618. 
Emery, N. J., \& Clayton, N. S. (2004). The mentality of crows: Convergent evolution of intelligence in corvids and apes. Science, 306, $1903-1907$.

Franz, M., \& Matthews, L. J. (2010). Social enhancement can create adaptive, arbitrary and maladaptive cultural traditions. Proceedings of the Royal Society of London: Biological Sciences, 277, 3363 - 3372.

Galef, B. G., \& Giraldeau, L. A. (2001). Social influence on foraging in vertebrates: Causal mechanisms and adaptive functions. Animal Behaviour, 61, 3 - 15.

Galef, B. G., \& Laland, K. N. (2005). Social learning in animals: Empirical studies and theoretical models. Bioscience, 55, $489-499$.

Green, M. L, Herzing, D. L., \& Baldwin, J. D. (2007). Noninvasive methodology for the sampling and extraction of DNA from free-ranging Atlantic spotted dolphins (Stenella frontalis). Molecular Ecology Notes, 7, 1287 1292.

Green, M. L., Herzing, D. L., \& Baldwin, J. D. (2011). Reproductive success of male Atlantic spotted dolphins (Stenella frontalis) revealed by noninvasive genetic analysis of paternity. Canadian Journal of Zoology, 89, $239-253$.

Harley, H. E. (2013). Consciousness in dolphins? A review of recent evidence. Journal of Comparative Physiology A, $199,565-582$.

Herman, L. M. (1980). Cetacean behavior: Mechanisms and functions. Malabar, FL: Krieger Publishing Company.

Herman, L. M. (2010). What laboratory research has told us about dolphin cognition. International Journal of Comparative Psychology, 23, 310 - 330.

Herman, L. M., Abichandani, S. L., Elhajj, A. N., Herman, E. Y. K., Sanchez, J. L., \& Pack, A. (1999). Dolphins (Tursiops truncatus) comprehend the referential character of the human pointing gesture. Journal of Comparative Psychology, 113, 347 - 364.

Herman, L. M., \& Gordon, J. A. (1974). Auditory delayed matching in the bottlenose dolphin. Journal of the Experimental Analysis of Behaviour, 21, 19-26.

Herman, L. M., Kuczaj, S., \& Holder, M. D. (1993). Responses to anomalous gestural sequences by a languagetrained dolphin: evidence for processing of semantic relations and syntactic information. Journal of Experimental Psychology: General, 122, 184 - 194.

Herman, L. M., Matus, D. S., Herman, E. Y. K., Ivancic, M., \& Pack, A. A. (2001). The bottlenosed dolphin's (Tursiops truncatus) understanding of gestures as symbolic representations of its body parts. Animal Learning \& Behavior, 29, $250-264$.

Herman, L. M., Richards, D. G., \& Wolz, J. P. (1984). Comprehension of sentences by bottlenosed dolphins. Cognition, 16, $129-219$.

Herzing, D. L. (1997). The life history of free-ranging Atlantic spotted dolphins (Stenella frontalis): Age classes, color phases, and female reproduction. Marine Mammal Science, 13, 576 - 595.

Herzing, D. L. (2000). Acoustics and social behavior of wild dolphins: Implications for a sound society. In W. W. $\mathrm{Au}$, A. N. Popper, \& R. R. Fay (Eds), Hearing by whales and dolphins, (pp. 225 - 272). New York, NY: Springer

Herzing, D. L. (2004). Social and non-social uses of echolocation in free-ranging Stenella frontalis and Tursiops truncatus. In J. A. Thomas (Ed), Advances in the study of echolocation in bats and dolphins (pp. $404-$ 410), Chicago, IL : University of Chicago Press.

Herzing, D. L. (2005). Transmission mechanisms of social learning in dolphins: Underwater observations of freeranging dolphins in the Bahamas. Autour de l'éthologie et de la cognition animale, 185 - 193.

Herzing, D. L. (2006). The currency of cognition: Assessing tools, techniques, and media for complex behavioral analysis. Aquatic Mammals, 32, $544-553$.

Herzing, D. L., \& Brunnick, B. J. (1997). Coefficients of association of reproductively active female Atlantic spotted dolphins, Stenella frontalis. Aquatic Mammals, 23, 155 - 162.

Herzing, D. L., \& dos Santos, M. (2004). Functional aspects of echolocation in dolphins. In J. A. Thomas (Ed), Advances in the study of echolocation in bats and dolphins (pp. 386 - 393). Chicago, IL: University of Chicago Press.

Herzing, D. L., \& Elliser, C. R. (2013). Directionality of sexual activities during mixed species encounters between Atlantic spotted dolphin (Stenella frontalis) and bottlenose dolphin (Tursiops truncatus). International Journal of Comparative Psychology, 26, $124-134$.

Herzing, D. L., \& Johnson, C. M. (1997). Interspecific interactions between Atlantic spotted dolphins (Stenella frontalis) and bottlenose dolphins (Tursiops truncatus) in the Bahamas, 1985-1995. Aquatic Mammals, 23, $85-99$. 
Herzing, D. L, Moewe, K., \& Brunnick, B.J. (2003). Interspecies interactions between Atlantic spotted dolphins, Stenella frontalis, and bottlenose dolphins, Tursiops truncatus, on Great Bahama Bank, Bahamas. Aquatic Mammals, 29, $335-341$.

Heyes, C. M. (1994). Social learning in animals: Categories and mechanisms. Biological Reviews of the Cambridge Philosophical Society, 69, $207-231$.

Heyes, C. M., \& Galef, B. G. (1996). Social learning in animals: The roots of culture. London, UK: London Academic Press Limited.

Highfill, L. E., \& Kuczaj II, S. A. (2007). Do bottlenose dolphins (Tursiops truncatus) have distinct and stable personalities? Aquatic Mammals, 33, $380-389$.

Hoppitt, W., \& Laland, K. N. (2008). Social processes influencing learning in animals: A review of the evidence. Advances in the study of behavior, 38, $105-165$.

Janik, V. M. (2000). Whistle matching in wild bottlenose dolphins (Tursiops truncatus). Science, 289, $1355-1357$.

Janik, V. M., Sayigh, L. S., \& Wells, R. S. (2006). Signature whistle shape conveys identity information to bottlenose dolphins. Proceedings of the National Academy of Sciences, 103, 8293 - 8297.

Jerison, H. J. (1986). The perceptual world of dolphins. In R. J. Schusterman, J. A. Thomas, \& F. J. Wood (Eds.) Dolphin cognition and behaviour: A comparative approach (pp. 141-166). Hillsdale, NJ: Lawrence Erlbaum Associates.

Jiang, Y., Lück, M., \& Parsons, E. C. M. (2007). Public awareness, education, and marine mammals in captivity. Tourism Review International, 11, 237 - 249.

Krützen, M., Mann, J., Heithaus, M. R., Connor, R. C., Bejder, L., \& Sherwin, W. B. (2005). Cultural transmission of tool use in bottlenose dolphins. Proceedings of the National Academy of Sciences of the United States of America, 102, $8939-8943$.

Kuczaj, S. A., Yeater, D. B., \& Highfill, L. (2012). How selective is social learning in dolphins? International Journal of Comparative Psychology, 25, $221-236$.

Kuczaj II, S. A., \& Yeater, D. B. (2006). Dolphin imitation: Who, what, when, and why? Aquatic Mammals, 32,413 $-422$.

Kuczaj, S. A., Makecha, R., Trone, M., Paulis, R. D., \& Ramos, J. (2006). Role of peers in cultural innovation and cultural transmission: Evidence from the play of dolphin calves. International Journal of Comparative Psychology, 19, $223-240$.

Kuczaj, S. A., Paulos, R. D., \& Ramos, J. A. (2005). Imitation in apes, children and dolphins: Implications for the ontogeny and phylogeny of symbolic representation. In L. L. Namy (Ed.), Symbol use and symbolic representation: Developmental and comparative perspectives (pp. 221 - 243). Mahwah, NJ: Erlbaum.

Laland, K. N. (2004). Social learning strategies. Animal Learning \& Behavior, 32, $4-14$.

Laland, K. N., \& Janik, V. M. (2006). The animal cultures debate. Trends in Ecology \& Evolution, $21,542-547$.

Laland, K. N., Richerson, P. J., \& Boyd, R. (1996). Developing a theory of animal social learning. In C. M. Heyes, \& B. G. Galef, Jr. (Eds.), Social learning in animals: The roots of culture (pp. 129-154), London, UK: London Academic Press.

Lammers, M. O., Au, W. W. L., \& Herzing, D. L. (2003). The broadband social acoustic signaling behavior of spinner and spotted dolphins. Journal of the Acoustical Society of America, 114, 1629 - 1639.

Lonsdorf, E. V. (2006). What is the role of mothers in the acquisition of termite-fishing behaviors in wild chimpanzees (Pan troglodytes schweinfurthii)? Animal Cognition, 9, 36 - 46.

Lusseau, D., \& Newman, M. E. J. (2004). Identifying the role that animals play in their social networks. Proceedings of the Royal Society of London: Biological Sciences, 271, S477 - S481.

Mann, J., \& Watsoncapps, J. (2005). Surviving at sea: Ecological and behavioural predictors of calf mortality in Indian Ocean bottlenose dolphins. Animal Behaviour, 69, $899-909$.

Marino, L., Connor, R. C., Fordyce, R. E., Herman, L. M., Hof, P. R., Lefebvre, L., \& Whitehead, H. (2007). Cetaceans have complex brains for complex cognition. PLoS Biology, 5, e139.

Mendl, M., \& Paul, E. (2004). Consciousness, emotion and animal welfare: insights from cognitive sciences. Animal Welfare, $13,17-25$.

Mercado, E., Uyeyama, R. K., Pack, A., \& Herman, L. M. (1999). Memory for action events in the bottlenosed dolphin. Animal Cognition, 2, $17-25$.

Miles, J., \& Herzing, D. L. (2003). Underwater analysis of the behavioural development of free-ranging Atlantic spotted dolphin (Stenella frontalis) calves (birth to 4 years of age). Aquatic Mammals, 29, 363 - 377.

Mineka, S., \& Cook, M. (1988). Social learning and the acquisition of snake fear in monkeys. In T. R. Zentall, \& B. G. Galef, Jr (Eds.), Social learning: Psychological and biological perspectives (pp. 51 - 73). Hillsdale, NJ: Lawrence Erlbaum Associates. 
Norris, K. S., \& Dohl, T. P. (1980). The structure and function of cetacean schools. In L. Herman (Ed.), Cetacean behavior: Mechanisms and functions (pp. 211 - 261). New York: Wiley.

Nicol, C. (1995). The social transmission of information and behaviour. Applied Animal Behaviour Science, $44,79-$ 98.

Nicol, C. (2004). Development, direction, and damage limitation: Social learning in domestic fowl. Learning \& Behavior, 32, $72-81$.

Nicol, C. (2004). Welfare of the laying hen (pp. 177 - 190). Wallingford, UK: CABI Publishing.

Nicol, C. (2006). How animals learn from each other. Applied Animal Behaviour Science, 100, 58 - 63.

Nicol, C. J., \& Pope, S. J. (1994). Social learning in small flocks of laying hens. Animal Behaviour, 47, $1289-$ 1296.

Nicol, C. J., \& Pope, S. J. (1999). The effects of demonstrator social status and prior foraging success on social learning in laying hens. Animal Behaviour, 57, $163-171$.

Oostindjer, M., Bolhuis, J. E., Mendl, M., Held, S., van der Brand, H., \& Kemp, B. (2011). Learning how to eat like a pig: Effectiveness of mechanisms for vertical social learning in piglets. Animal Behaviour, 82, 503 - 511.

Pack, A., \& Herman, L. M. (2006). Dolphin social cognition and joint attention: our current understanding. Aquatic Mammals, 32, 443 - 460.

Palameta, B., \& Lefebvre, L. (1985). The social transmission of a food-finding technique in pigeons: What is learned? Animal Behaviour, 33, $892-896$.

Perrin, W. F. (1970). Color pattern of the Eastern Pacific spotted porpoise Stenella graffmani Lonnberg (Cetacea, Delphinidae). Zoologica, 54,135 - 149.

Pongrácz, P., Miklósi, Á., Kubinyi, E., Topál, J., \& Csányi, V. (2003). Interaction between individual experience and social learning in dogs. Animal Behaviour, 65, $595-603$.

Reiss, D., \& Marino, L. (2001). Mirror self-recognition in the bottlenose dolphin: A case of cognitive convergence. Proceedings of the National Academy of Sciences, 98, 5937 - 5942.

Rendell, L., \& Whitehead, H. (2001). Culture in whales and dolphins. Behavioral and Brain Sciences, $24,309-$ 382.

Ridgeway, S. H. (1986). Physiological observations on dolphin brains. In R. J. Schusterman, J. A. Thomas, \& F. J. Wood (Eds.) Dolphin cognition and behaviour: A comparative approach (pp. 31 - 59). Hillsdale, NJ: Lawrence Erlbaum Associates.

Sherwin, C. M., Heyes, C. M., \& Nicol, C. J. (2002). Social learning influences the preferences of domestic hens for novel food. Animal Behaviour, 63, 933 - 942.

Snyder, N. F. R., Derrickson, S. R., Beissinger, S. R., Wiley, J. W., Smith, T. B., Toone, W. D., \& Miller, B. (1996). Limitations of captive breeding in endangered species recovery. Conservation Biology, 10, 338-348.

Tanida, H., \& Nagano, Y. (1998). The ability of miniature pigs to discriminate between a stranger and their familiar handler. Applied Animal Behaviour Science, 56, 149 - 159.

Thompson, R. K. R., \& Herman, L. M. (1981). Auditory delayed discriminations by the dolphin: nonequivalence with delayed-matching performance. Animal Learning \& Behavior, 9, 9 - 15.

Thompson, R. K. R., \& Herman, L. M. (1977). Memory for lists of sounds by the bottle-nosed dolphin: Convergence of memory processes with humans?. Science, 195, $501-503$.

Thornton, A., \& Raihani, N.J. (2010). Identifying teaching in wild animals. Learning \& Behavior, 38,297 - 309.

Tomasello, M., \& Call, J. (1997). Primate cognition. New York, NY: Oxford University Press,.

Tomasello, M., Davis-Dasilva, M., Camak, L., \& Bard, K. (1987). Observational learning of tool-use by young chimpanzees. Human Evolution, 2, 175 - 183.

Visalberghi, E. (1987). Acquisition of nut-cracking behaviour by two capuchin monkeys, Cebus appella. Folia Primatologica, 49, $168-181$.

Whitehead, H., \& Rendell, L. (2015). The cultural lives of whales and dolphins (pp. 10 - 44). Chicago, IL: University of Chicago Press.

Whitehead, H., Rendell, L., Osborne, R. W., \& Würsig, B. (2004). Culture and conservation of non-humans with reference to whales and dolphins: Review and new directions. Biological Conservation, 120, $431-441$.

Wechsler, B., \& Lea, S. E. G. (2007). Adaptation by learning: Its significance for farm animal husbandry. Applied Animal Behaviour Science, 108, 197 - 214.

Welsh, L. S., \& Herzing, D. L. (2008). Preferential association among kin exhibited in a population of Atlantic spotted dolphins (Stenella frontalis). International Journal of Comparative Psychology, 21, $1-11$.

Whiten, A. (2000). Primate culture and social learning. Cognitive Science, 24, 477 - 508. 
Whiten, A., \& Ham, R. (1992). On the nature and evolution of imitation in the animal kingdom: Reappraisal of a century of research. In P. J. B. Slater, J. S. Rosenblatt, C. Beer, \& M. Milinski (Eds.), Advances in the study of behavior (pp. 239 - 283). San Diego, CA: Academic Press.

Whiten, A., Horner, V., Litchfield, C. A., \& Marshall-Pescini, S. (2004). How do apes ape? Learning \& Behavior, $32,36-52$.

Wilson, D. S., Clark, A. B., Clark, A., Coleman, K., \& Dearstyne, T. (1994). Shyness and boldness in humans and other animals. Trends in Ecology \& Evolution, 9, $442-446$.

Wood, F. G., \& Evans, W. E. (1980). Adaptiveness and ecology of echolocation in toothed whales. In R. G. Busnel, \& J. F. Fish (Eds.) Animal sonar systems (pp. 381 - 426). New York, NY: Plenum Press.

Xitco, M. J., Gory, J. D., \& Kuczaj, S. A. (2004). Dolphin pointing is linked to the attentional behavior of a receiver. Animal Cognition, 7, $231-238$.

Yeater, D. B., \& Kuczaj II, S. A. (2010). Observational learning in wild and captive dolphins. International Journal of Comparative Psychology, 23, $379-385$.

Zentall, T. R. (2003). Imitation by animals: How do they do it? Current directions in Psychological Science, 12, 91 -95 . 